\title{
A Philosophy of Computing? - The Case of Sociology and Computing
}

\author{
HUGH ROBINSON
}

Computing Department, Faculty of Mathematics, The Open University, Walton Hall, Milton Keynes, MK7 6AA, United Kingdom

\section{CONTENTS}






\section{Synopsis}

I discuss the contributions to computing of two strands of sociology, the sociology of scientific knowledge and ethnomethodological ethnography, with a view to developing a philosophy of computing. Such contributions are not unproblematic, yet they serve also to illuminate the nature of computing as a social and technical enterprise that is rooted in practice. The likelihood of immediate prescriptive engineering contributions from such sociologies is viewed with a healthy scepticism. However, the utility of such contributions in establishing a reflective discipline, with reflective practitioners, is seen to be a great value.

\section{Key Words}

Philosophy of computing, sociology of scientific knowledge, ethnomethodology, ethnography, reflective practice, formalisms.

\section{Introduction}

The broad rubric of this special issue is to explore the ways in which findings from the social sciences have had, and will continue to have, an impact on the design of intelligent systems. The title of my paper indicates a concern for the development of a philosophy of computing. As a means of setting the substance of my paper in a context, I want to begin by exploring the relationship (and constructive tension) between this rubric and my title. Put brutally, I examine and analyse the kinds of contributions sociology makes to computing in order to better understand the nature of computing: what it means to make progress in computing and what it means to acquire knowledge that is distinctively 'computing' knowledge. Less prosaically, I argue 
that the contributions of sociology to computing are not unproblematic and that neither is the nature of computing. However, such intentions should not be seen as negative. Put polemically, I see the nature of computing as problematic only because I argue for a richer conception than that which is ordinarily taken to be the case. In a similar vein, I see the contributions of sociology as problematic because they, in one sense, argue for a more critical appraisal of what it is to do computing.

I begin by describing the particular construction I give to the terms 'computer science', 'philosophy of computing' and 'sociology'.

\section{Computer Science}

I take computer science to be an applicational science: that is, it is concerned with practitioners and practice, with the business of the effective construction of software, of designing and creating enduring artefacts that take their place in the world's work. I subscribe to no belief in the primacy of theory over practice. I reject the notion that Fractitioners and practice can be viewed adequately through the lens of a relentless technological determinism (such as that espoused in Codd 1989 , for example, where theory is seen as the driving force that changes practice). Rather, I see the socio-historic perspective, as given classically by Kuhn (1970), as having direct relevance to an adequate understanding of the business of creating what, ultimately, is program code. This is not a conventional view of computer science, but it is one that has been argued for by others, most recently by Leith (1990). By way of illustration, I offer these typical passages from Leith's recent text.

However, computer science, of all disciplines, should be able to set aside this false dichotomy between research and development, for surely all our research is into the 
development of new applisations for computing or improving the operation of existing applications. Computer science is an applicational science, technology or discipline, whatever one wishes to call it. ... That the way that computer science happens is not the unfolding of strict truths, but rather is a battlefield where the views of participants owe as much to their notions of "what the world is" as to any technical notions of computer or program. This is an argument that computer science, like all sciences, is a social phenomenon. (Leith 1990, pp. 48-49)

All of this stands against the 'hard science' tradition in computer science that seeks to emphasise its parity with the perceived rigour of mathematics and the physical sciences. This desire for the cachet of 'science' and the characterisation of non-science as nonsense is well illustrated by Hoare's (1984) "Programming: sorcery or science?" or Milner's (1986) inaugural lecture for the Laboratory for Foundations of Computer Science, entitled "Is computing an experimental science?" The questions are, of course, rhetorical: Hoare believes programming is science and Milner believes computing to be an experimental science. The rhetoric works because we are already persuaded of science as the paradigm of knowledge which is certain, rigorous and objective, as given by Galileo (1967, pp. 53-54).

If what we are discussing were a point of law or of the humanities, in which neither true nor false exists, one might trust in subtlety of mind and readiness of tongue and in the greater experience of the writers, and expect him who excelled in those things to make his reasoning most plausible, and one might judge it to be the best. But in the natural sciences, whose conclusions are true and necessary and have nothing to do with human will, one must take care not to place onself in the defence of error; ... 
We are persuaded because this is an ideology, where science is seen not merely as a paradigm of a certain kind of knowledge but as the defining paradigm for all knowledge. Ravetz (1973, p. 12) expresses it thus.

The areas of ordinary life where inherited craft-wisdom is valued more highly than the judgements of scientific experts, are shrinking down to the vanishing point. ... A sign of the triumph of 'science' is the reliance on textbooks for such personal crafts as rearing children and even achieving a happy married life.

I choose this juxtaposition with the 'hard science' paradigm not as some vitriolic aside against scientism in computer science, but as emphasis for my concerns in understanding (and even improving) the creation of the products of a particular technology. I claim illumination and insight for that technology, that applicational science of computing (or whatever): I make no such claims for insight into sociology.

\section{Philosophy of Computing}

One rendition of the philosophy of science is that it is concerned with the explication of what science is and what it means to do science. That is to say, it addresses questions such as those offered by Toulmin (1953).

How do physicists in fact decide that an explanation is acceptable? What sort of job must an expression perform to qualify for the title of 'law of nature'; and how do laws of nature differ from hypotheses? ... And as for these new entities scientists talk so much about genes, electrons, meson fields and so on - how far are they thought of as really existing, and how far as mere explanatory devices? (ibid., p. 11). 
A simple, yet useful, artifice to illustrate the intent of a philosophy of computing is that of substituting 'conceptual data model' for 'explanation', 'normalised entity' for 'law of nature' and 'functional dependencies' for 'hypotheses' 1 . An important characteristic of such a philosophy of computing is that it is empirically grounded. Toulmin puts matters thus.

... one can continue to write about 'Causation and its Place in Modern Science' indefinitely, if one fails to notice how rarely the word 'cause' appears in the writing of professional scientists. Yet there are good reasons for this rarity, and to ignore them is to again divorce the philosophical discussion of scientific arguments from the reality. (Toulmin, op. cit., p. 10)

Given this, a philosophy of computing needs to be not just 'philosophy' but to also incorporate the concerns of the empirically grounded sociology of scientific knowledge (see Woolgar 1988 for an excellent introduction) and the 'historical' concerns of the Kuhnian tradition (Kuhn 1970).

At the risk of over-emphasising my point, I would like to juxtapose my rendition of a philosophy of computing against an example from a completely different discipline: that of nursing. Nursing, in the late 1970's and early 1980's, went through a complex process of re-evaluation that, at least in part, was concerned with comprehending the contributions from other disciplines (such as the social sciences) to nursing and attempting to establish what was distinctive about nursing knowledge (as opposed to other forms of

1 These suusututions come from my own area of interest: that of database technology. The reader is invited to create other substitutions appropriate to their own area of expertise. 
knowledge, such as medical knowledge). The example that I use comes from the 'investigation' debate into the nature of health visiting, instigated by the (now defunct) Council for the Education and Training of Health Visitors (CETHV). Here is an extract from the position paper presented by an academic nurse - Ruth Schrock.

No one would doubt that there is a group of people called health visitors. They exist, they carry out observable activities which can be described and categorised and compared with the activities of other people. These are matters of fact, open to verification. ... But this does not answer the question whether there is such a cognitive, conceptual entity which we can call health visiting as distinct from similar but other entities. So what we are encountering here is a conceptual problem. To find the answer we would waste time, if we tried to learn more about health visitors, or about their work as it can be seen to be done, or about the things which they learn in the course of their training and education. We must focus our attention on the criteria in virtue of which we say that all these factual phenomena can be conceptualised under the term 'health visiting'. (CETHV 1977, p. 68)

Whether Schrock was right or wrong for health visiting is neither here nor there for my purposes. The point that I wish to make is that the particular philosophy of computing that I am exploring is not one that conceives itself as dealing exclusively with conceptualising or conceptual problems. Rather, it is a philosophy that attends to practitioners' work as it can be seen to be done and about the things they learn in the course of their education and training.

\section{Sociology}

I have deliberately used the term 'sociology' rather than the 'social science' of the rubric of this special issue. I do this not to make 
any point about ascription of the term 'science' but rather to emphasise that I make no claims about the contributions of psychology, ergonomics, cognitive science or whatever. Rather, I emphasise the contribution of two (related) strands of sociology: those which, at the risk of simplification, can be termed the sociology of scientific knowledge and ethnomethodological ethnography.

What then of the contributions of such sociologies to computing and the way in which they illuminate the nature of computing; the way in which they construct a philosophy of computing? I look first at the contributions from the sociology of scientific knowledge.

\section{The Sociology of Scientific Knowledge}

Such a sociology admits that scientific knowledge is as much socially constructed knowledge as any other knowledge: that scientific facts are as much created as 'discovered' and that 'true' science is as much the object of sociological study as 'false' science (see Bloor 1976 on this lack of distinction between the 'true' and the 'false' and Woolgar 1988 or Latour 1987 for two accessible accounts of the sociology of scientific knowledge). In terms of what I have said above, such a sociology is attractive in 'that a sociological understanding of the construction of scientific knowledge requires a sophisticated appreciation of the technical content of the knowledge at issue and, preferably, a close contemporaneous investigation of scientists' technical endeavours.' (Woolgar 1988, p. 41). That is to say, for my purposes, it places emphasis on practice and practitioners.

I will concentrate largely on one contribution from this area: that of Leith (1990). I do this for a variety of reasons. Leith occupies the same ambiguous ground that I claim for myself: that of a computer 
scientist attempting to gain a greater comprehension of computing from the perspectives of other disciplines. The aspect of his work under consideration is about the place of mathematics and logic in computing and is directly concerned with intelligent information systems and, interestingly, we have some perspective on how contributions such as his have been received within the discipline of computing. Of course, there are other contributions directed at computing under the broad heading of the sociology of scientific knowledge (Woolgar 1985 and Collins 1990 being two examples).

It is invidious, misleading and difficult to summarise complex and sophisticated works in a few sentences, doing justice to both the intent of the author and the perceptions of the account being offered of the author's work, but, for my purposes, Leith is mounting two arguments. The first is concerned with the role of formalism, in the guise of logic, in artificial intelligence, specifically in the area of expert systems. The second is concerned with the role of formalism, in the guise of mathematics, in software engineering.

Taking the area of expert systems, the case can be expressed by the slogan that epistemology cannot be reduced to logic. That is to say, Leith demonstrates that the formalist position of treating expertise as being capable of encapsulation in a computer program by emphasising the role of rules as the prime agent of knowledge is radically misconceived.

Simply put, the never ending need to set out that which goes to make up common sense, and the difficulty of expressing this invisible - yet simple - personal knowledge, make it impossible to extract an expert's knowledge in a manner sufficient to replace him with a machine. (Leith 1990, pp. 159-160) 
Support for such assertions are provided by Leith from a range of sources: Collins (1988), and Leith's (1986) (in)famous study of law and legal logic programming, for example. Yet they echo and rehearse other support that could be cited. Wittgenstein (1958) and Garfinkel (1967) can at least be read as demonstrating that human behaviour orients to and constructs rules rather than being rule governed. Garfinkel (1967, pp. 24-31) describes the particular methodological horror that goes with the setting out of assumptions - 'common sense' - in that 'it is always possible to ask for further clarification, elaboration, elucidation and the like' (Woolgar 1988, p. 32). Work from quite different areas and concerns can be marshalled to support Leith's position. For example, the work of Dowie \& Elstein (1988) suggests that clinical wisdom and expertise resides in the synthesising of conventionally legitimated knowledge and practice, with little or no recourse being made to systematic analysis in the pursuit of problem solving. Somewhat similarly, Brody $(1986,1987)$, Lopez (1986) and Suchman (1987) have all reported on behaviour that is clearly of a highly expert nature yet, equally clearly, is not capable of reduction to the simple application of rules and facts. These empirically based studies all emphasise the situated and negotiated nature of expertise and that expertise, fundamentally, is something displayed by experts (rather than being a distinct and separate commodity) as part of a particular social context.

All this amounts to an intensely practical problem for computing. Expert systems are produced as artefacts in the world, but what is the world to make of them? As I have put it elsewhere (Robinson 1991): 'How does a nurse respond to ... some patient care planning software ... that recommends a particular form of patient care to him for a particular patient in his charge? The computer system makes the 
recommendation and lays claim to the authority of knowledge. Is this knowledge entirely equivalent to that of a senior nurse giving the same recommendation?' Leith (1986, p. 551) has no doubts as to what the answer should be: 'Hence, I can only reiterate the advice to potential immigrants or those concerned with their nationality to discuss the problem with an expert; not with a legal rule- or logic-based expert system. The advice they would get could not possibly be worse.'

An adjunct to Leith's position is a view that logic, the medium for the rendition of rules, is itself problematic and that part of the seduction of expertise-as-rule-governed-behaviour stems from an unquestioning belief in the immutable certainty of logic. This is a certainty not so much claimed by logicians (see Carroll 1895, for example) as by those who invoke logic as a transcendent epistemology that can be applied, willy nilly, to the real world of practical expertise, framing and dealing with practical problems. That is, we see logic texts, to use Fuller's (1987, p. 2) characterisation, as 'being authored by someone whose cognitive processes captured some socio-historically invariant piece of reality'. Or, as Nye, in beginning her account that logic is not transcendent truth but abstract forms of language - 'words of power' spoken by men, puts it:

Logic proclaims itself the unreadable language, the language which has detached itself from confusion and passion, the language which has transcended natural language embedded in sensual lives, mutably imprinted with social, economic, or personal concerns. The logician does not speak; he does not tell the truth; he exhibits it. All vestiges of his speaking voice are transcended, all reference to his situation, to his sex, his place in time or space. Logic is the perfect transparency of a language which does not need to be read. (Nye 1990 , p. 4) 
Lest this questioning of the technicalist belief in the power of logic be viewed as the mere sophistry of lawyers and philosophers, I offer an example from my own area of interest: the more mundane world of database technology. The problem of extending conventional two-valued logic to missing data in a relational database seems trivial enough: we seem to require just an appropriate extension - three-valued logic - to this immutable and objective tool. Yet the 'power' of logic raises more problems than it begs, as the practical debate laid out in Date (1986), for example, shows. Having given a treatment of null values (the approach used in the application of three-valued logic) which Date (1986, p. 322) claims to be 'as reasonable as any that has been given in the literature', he describes a series of intuitive difficulties (arising primarily from the counter-intuitive nature of three-valued logic) and implementation anomalies (arising from the fact that system implementors are human too, and are therefore just as liable to get confused as anybody else). He concludes:

... that there seems to be no "right" answer to certain questions. The example lends support to the view that the sum of an empty set should be zero, not null; yet how could one then distinguish (in the context of SUM) between an empty set and a non-empty set whose elements happen to add up to zero? (Date 1986, p. 330).

Date abandons null values for a scheme based on default values that is less ambitious but more straightforward in dealing with missing information.

At this point, it is worth stating what I hope is obvious. I am not seeking to deny logic (or, more generally, the technical). I happily employ logic (and the technical) in my own teaching and practice in the construction of database systems. What I am seeking to deny, or 
question, is a certain set of claims made about the use to which logic can be put.

I now turn, more briefly, to Leith's considerations on formalism, in the guise of discrete mathematics, in software engineering. A similar argument for the social dimension in the creation of software is made, coupled with the demonstration of the oppression of that dimension by formalism. Much of what Leith articulates is through the rhetoric of software engineering juxtaposed against the realities of producing software in a world that is inextricably social, and he rightly stresses the paucity of empirical evidence to give any support for the programmatic claims of formalism (Leith 1990, p. 172). Yet, underlying all of this is a characteristic feature of doing computing - that of abstraction. In the words of Shaw (1984):

An abstraction is a simplified description ... of a system that emphasises some of the system's details or properties while suppressing others. A good abstraction is one in which information that is significant to the reader ... is emphasised, and details that are immaterial or diversionary, at lest for the moment are suppressed.

The position of formalism is one where what is emphasised is that which can be expressed in the language of science, conceived of as mathematics and logic, and what is immaterial or diversionary is that which cannot be so expressed - inevitably, the recognition that the production and use of code is a human and social activity. This is a position that is not unique by any means to software engineering. Much of the history of recent database technology can be read as a belief in (a separate and enduring) reality being capable of description in a formal language. That description - the conceptual schema - is seen as different from the mundane accounts of the real world in that it obeys the conceptualisation principle of ISO (1982). 
A conceptual schema should only include conceptually relevant aspects ... of the universe of discourse, thus excluding all aspects of (external or internal) data representation ... as well as all aspects of particular external user representation ... (ibid., p. 1-9)

That is to say, a user's (the person for whom the software artefact has nominally been created) view of the world is precisely not acceptable! As with the material discussed by Leith, the primacy of logic and mathematics comes to the fore as the appropriate linguistic vehicle for the articulation of a conceptual schema. Indeed, some writers, such as Steel (1985), would appear to conceive conceptual data modelling as being essentually mathematics. To be fair to such writers, they conceive of most things as being essentially mathematics.

The position of formalism within software engineering - that of excluding the social nature of computing and the social construction of knowledge in computing - stands at some odds with the polemic of software engineering itself. Standard texts proclaim the construction of artefacts by teams of people, concerned with non-technical as well as technical aspects (see Sommerville 1989, p. 3 for a tertiary education example and UDACE 1991, pp. 23-31 for a professional articulation). Further twists emerge when the journal of a professional body, much concerned with establishing the professional engineering qualification of CEng for software engineers, publicly disavows its own profession's concern for the non-technical by proscribing any paper that is not 'devoted solely to reports of new technical developments in computer science and computer applications'. (Computer Journal 1987) ${ }^{2}$

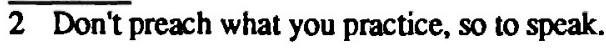


Some Preliminary Remarks on 'Contributions'

Where does all this get us? What are the contributions of sociology? I choose to give three preliminary answers.

Firstly, there is a sense of revelation in such contributions by virtue of irony: the preachings of computing do not accord with the practice of computing. The sociology of scientific knowledge holds a mirror, so to speak, to computing, by virtue of which it may reflect upon itself as a discipline, saying 'here is how you (really) look'3. And this is not entirely difficult to do, given the self-obsessive hype of the claims of computing (see Benyon 1991 for just one, not untypical, example) or the confused and confusing 'critiques' that have been produced in some areas (see Penrose 1990, for example): 'Through their own words, they will be exposed. They've got a sudden case of the emperor's new clothes' (O'Connor 1990). This irony is refreshing and no bad thing, if it results in us ('computer scientists') losing some hubris. That irony is conceived as a more central problem to sociology (see Woolgar 1983) is a problem for them ('sociologists'). So, this contribution is simply one 'that debunks the subject with serious intent ...' (Saxby 1991).

Secondly, there is the implicit injunction that certain technical enterprises are fatally flawed - that, for example, expert systems, as conceived by their advocates cannot and could not do what is claimed for them. This is not to deny expert systems (they exist) but to attempt to re-cast and re-formulate the expectations that can be placed upon

3 Sociologists of scientific knowledge would, of course, deny such a claim, in view of methodological adequacy: 'what grounds provide the warrant for the relationship between the objects of study and the statements made about those statements?' (Woolgar 1988, p. 31). 
them. For example, Leith has considerable more sympathy for the notion of a decision support system, albeit with the reservation that the concept of an expert system is not necessarily the best place to begin to understand the business of building decision support systems for intellectual workers (Leith 1990, p. 162). There is some evidence that such an injunction has effect: at a recent conference on information technology and nursing (Nursing Specialist Group 1990) considerable effort was made by presenters of patient care planning systems to stress the 'support' aspect of such systems and to downplay the 'expertise' aspect (see von Grey 1990). Of course, how much of this effort is rhetoric geared to a people-centered profession, such as nursing, is open to debate. However, there is an unreality in the expectation of such a contribution. We (computer scientists of a social bent) make the sign of the cross and drive down our epistemological stake into their (computer scientists of a technicalist bent) heart and expect the vampire to die. But nothing happens; no one is persuaded of the error of their ways. As Ronald Brachman observes 'Regardless of the ultimate cogency of arguments against formal AI, work in [knowledge representation] proceeded without heed.' (quoted in Ryan 1991, p. 242).

Thirdly, and finally, there is the issue of the tension between theory and practice: that much useful contribution can be gained by attending to what practitioners do, rather than what we might imagine them to be engaged in. Part and parcel of this is the wider issue of the relevance of academic research to practical development, and the appropriateness or otherwise of tertiary education courses in computing to professional practice (see Henderson 1991 as one example of a debate that continues to surface). 


\section{Ethnomethodological Ethnography}

The very kind of words used for this strand of sociology seem to have two effects on professors of computer science that is an illuminating observation in its own right. One reaction is that of almost a love affair with the exotic: the words speak of new (liberal, human, intellectual?) dimensions outside those of the mundane world of computing 4 . The other is a rabid desire never to hear such gobbledegook again. To begin with, the terms are worth a little unpacking. At the risk of gross simplification, ethnography 'is a style of research in which the observer adopts the stance of an anthropologist coming upon the phenomenon for the first time.' (Woolgar 1988, p. 84). A very quick, but highly effective, introduction to the ethnographic style is given by Xargle $(1988,1989)$, particularly with her observation that earthlets come in four colours - pink, red, brown and yellow - but not in the colour green. More conventional introductions can be found by Hammersley \& Atkinson (1983) and Silverman (1985). Ethnomethodology comes from Garfinkel (1967) with the injunction to attend to the mundane activities and resources by which members (of what amounts to a Wittgensteinian language game) manage the practical accomplishment of everyday live - the ethnomethods which they employ5.

For me, ethnographic ethnomethodology is a significant strand of sociology for several reasons. Trivially, one variant of ethnomethodology, what Heritage (1984, pp. 293-304) has called the studies-of-

4 The author of this paper would not claim to be immune to such seduction.

5 Thus, to the sometime confusion of computer scientists, ethnomethodology is not a 'methodology' in the sense of SSADM (see Ashworth \& Goodland 1990) being a methodology, although what gets carried out in mundane business of SSADM might well be ethnomethods! 
work programme, has much in common with the techniques used by many in the sociology of scientific knowledge (although it has a wider applicability). Less trivially, the work of Suchman (1987) within this strand has had a significant impact on one area of computing: human computer interaction $(\mathrm{HCl})$. Suchman's work emphasises the situated and contingent nature of interaction with computers and construes software states and tasks as resources for members' reasoning about interaction, as opposed to being determinants of interaction. All this is achieved by a close attention to the fine grain of empirical detail, producing 'hard facts' 6 . Coupled with the impetus of Suchman's work, are developments that seize upon the findings of one particular form of ethnomethodological work, that of conversation analysis, which emphasises the practical reasoning displayed in the organisation of conversation: opening conversation, turn-taking within conversation, the repair of breakdown within conversation and the closing of conversation - a set of tacit, normative and reciprocal rules to which partners orient when doing conversation (see Sacks, Schegloff \& Jefferson 1974 for the classic account).

A suggestive line of direct contribution for ethnomethodology is that of engineering human computer interaction so that it exhibits just this practical reasoning displayed in conversation. Conversations with computers would then exhibit the turn-taking, repair of breakdown, etc. of mundane conversation. Mundane conversation is assumed to exhibit the natural and 'user-friendly' quality that is a desired feature of human computer interaction. Thus, findings in a relatively obscure area of sociology are seen as capable of making a major impact on a significant

6 There is a tendency to view such accounts as being 'how it really is'. As already noted, in footnote 3., this realist epistemology is theoretically dubious but, forall-practical-purposes, is taken to be the case. 
area of computing. Work in this direction is discussed in the collection of Luff, Gilbert \& Frohlich (1990). This collection offers a bewildering vista to a computer scientist. On the one hand, there are accounts of social scientists engineering social structures into human computer interaction to provide better interface artefacts (Norman \& Thomas 1990, Frohlich \& Luff 1990, Gilbert, Wooffitt \& Fraser 1990) - at last, hard contributions to intelligent information systems from sociologists!? On the other, there are sociologists demonstrating that such engineering is fatally flawed and leads up a blind alley, albeit welllit (Button 1990). But the conviction of hard contributions seems to be backed by hard cash, in the sense that many major computer companies are willing to employ sociologists in an attempt to ensure that their computers are not socially disadvantaged, in a landscape dominated by the rhetoric of compassion for the user.

Lest this be seen as a tantalising (in)conclusion, let me say that I see it as evidence of a richness in the sociology, in that the sociology, in one sense, can be seen as suggesting that these are largely empirical questions. As I have mentioned elsewhere, the question of whether or not human computer interaction is a form of conversation is rendered as the question 'when, and under what circumstances, does the interaction display the managed accomplishment of conversation?' (Robinson 1990 , p. 47). Read as a prescription, the sociology at least contains some way of evaluating the execution of the prescription. This is significant, given that other conversation systems, as well as mundane conversation, exist and show differences in the practical reasoning that is displayed. The pre-allocation of turn-taking (Atkinson and Drew 1979 ) or the orchestration of turn-taking (Dingwall 1980, Robinson 1987) may be appropriate structures to engineer into human computer interaction in particular situations. 
Some More Preliminary Remarks on 'Contributions'

So, does this lead me to the conclusion that sociology contributes by healthy doses of de-bunking to relieve hubris, etc. (from the sociology of scientific knowledge) and better interfaces (from ethnomethodology)? The rhetoric that I have employed leads to caution in any positive answer.

The design of better interfaces via informed ethnomethodology is not unproblematic, as I have argued elsewhere (Robinson 1990, p. 47). Indeed, there is an immense gulf between statements of how things are (in mundane telephone conversations or in the use of an expert system for a photo-copier, or whatever) to how things ought to be (in terms of some new interface, engineered with the practical reasoning of turntaking, or whatever). In terms of the morality of cognition, it is the old is/ought gap of Hume (1911). To quote both the fashionable and unfashionable: philosophy 'leaves everything as it is' (Wittgenstein 1958 , p. 49), 'The philosophers have only interpreted the world in various ways, the point is to change it.' (Marx 1976, p. 5). Suchman's (1987) study is outstanding, yet her conclusions are disappointing if one looks for engineering prescriptions. She calls for an alternative approach to HCI studies based on three elements (Suchman 1987, p. 179): a change in perspective to take on board the situated and contingent nature of action as being intrinsic to the problem in hand, a renewed commitment to grounding theories of action in empirical evidence, and a recognition that the coherence of action is not adequately explained by preconceived cognitive schema or institutionalized norms. I have no quarrel with such programmatic concerns, and it may be the best that we can expect, but it does not constitute any prescription to act upon the world in the direct way that software engineers conceive 
themselves as doing. This is a harsh and unfair criticism (see Robinson 1990 , p. 49), but there is a danger that sociology (as ethnomethodological ethnography) is being seduced into the very hype that has bedevilled expert systems and formal methods. Perhaps, ten years on, some letter will be written to the Higher, complaining about this treatment of sociology in terms similar to that of Wilks (1991):

'... unrealistic expectations about AI's progress have been raised in the past and still are, but the fault is not really in the AI researchers themselves. Funders ... encourage and support fashionable but unrealistic claims, and researchers, anxious to continue their work at any cost like their colleagues in most disciplines, respond by producing claims as unrealistic as are required.'

This is not yet quite the case and engineering prescriptions, such as those of Gilbert, Wooffitt \& Fraser (1990) are notable for their cautious rhetoric 7 .

\section{Carpet Bagging and Reconstruction}

Part of the burden of what I have been arguing for is that computing is both technical and 'socio-historic-philosophic' and that any understanding of computing and the knowledge that it lays claim to must incorporate both these aspects. My argument has been by limited example: two strands of sociology. Yet, of course, there is much more. For example, there is the participative approach to systems design (see Mumford, Land \& Hawgood 1987, for example). There is

7 In part this is a feature of the particular irony noted by Gilbert, Wooffitt \& Fraser (1990, p. 242). 
also a continental European tradition where a free move is made from how things are to how things ought to be, having no pre-occupation with empirical accounts, and advocating radical changes to information systems analysis and design that are predicated on a disdain for the scientism that pervades computer science. The general flavour of this approach can be gleaned from the paper of Klein \& Hirschheim (1987) and its associated citations.

With this caveat taken care of, I come to the central issues of this section. Computer scientists are concerned with computing (with all the dimensions I have argued for) and sociologists are concerned with the social (and historians with the historical, etc.). To state the obvious: they are constructed as separate disciplines, with separate concerns. That is not to say that the one cannot influence the other, but it is to say that such an influence needs to be treated with caution. Ideas from one discipline cannot be imported, free from intellectual baggage, into another. Much of the symposium reported in Luff, Gilbert \& Frohlich (1990) could have been characterised as epic misreadings of sociology by computer scientists (just as this paper might be so construed). To carry out the kind of programme advocated by Suchman (1987, p. 179) requires patience, hard work and a realisation that tangible results may come by a different timescale to that expected by computer science. Sociologists should be suspicious of the warm bed offered by the invitation to computing. There is another side to this coin, as can be appreciated by taking an example from another area, medicine. Realising that it had a social as well as technical side ( $c f$. 'patients' as 'users'), medicine began an affair with sociology sociology for medicine - that proved sufficiently seductive to sociology to define medical sociology and an exclusive concern with the social (and neglect of the technical), giving rise to a form of sociological 
imperialism (see Strong 1979). From this point of view, the practical advice to computer scientists might be to be beware of sociologists bearing gifts and, to sociologists, to take the money and run.

Yet, this is to deny what has been achieved. Computing knowledge is worthy of studies beyond the mere technical. An understanding of the role of abstraction in computing, an analysis of the belief in the efficacy of methods in analysis and design, the place of mathematics and logic in computing, a (non-Whig) history of relational database technology, etc. contribute to a discipline that is capable of reflecting upon itself. That sociology has something to offer in that reflective process should be no more remarkable than the belief that computer science has a social dimension on a par with a technical dimension.

Somewhat more remarkably, this belief in a reflective discipline is suggestive of a reflective practitioner, in the spirit of Schön (1983, 1987). A comprehension of a philosophy of computing carries with it injunctions for cducation. In our teaching of, say, the object oriented paradigm to replace the store/imperative paradigm, we should not be concerned exclusively with replacing one paradigm with another in the heads of our students ('practitioners-to-be'?). Rather, we should also attend to the business of teaching what paradigms in computing achieve, how they are chosen, and what shifting from one to another entails. Achieving that - an epistemology of professional practice which opposes 'reflective' to the 'technocratic' - ought to constitute an impact on the design of intelligent information systems. Contributions. will be gratefully received. 


\section{References}

of Sociology and Computing

Ashmore M., Mulkay M., \& Pinch T., 1989, Health and Efficiency: a Sociology of Health Economics, Milton Keynes, Open University Press.

Ashworth C., \& Goodland M., 1990, SSADM: A Practical Approach, London, McGraw-Hill.

Atkinson J.M., \& Drew P., 1979, Order in Court: the Organisation of Verbal Interaction in Judicial Settings, London, Macmillan.

Benyon D., 1991, Review of The Art of Human-Computer Interface Design (edited by Laurel B., Wokingham, Addison-Wesley, 1990), Computer Bulletin, 3 Part 4, p. 27.

Bloor D., 1976, Knowledge and Social Imagery, London, Routledge and Kegan Paul.

Brody H., 1986, Maps and Dreams, London, Faber \& Faber.

Brody H., 1987, Living Arctic, London, Faber \& Faber.

Button G., 1990, Going up a blind alley, in Luff, Gilbert \& Frohlich (1990)

Carroll L., 1895, What the Tortoise said to Achilles, Mind, 4, 14, cited in Leith (1990).

CETHV 1977, An Investigation into the Principles of Health Visiting, London, Council for the Education and Training of Health Visitors.

Codd E. F., 1989, From theory to practice, The Relational Journal, Issue 8, November 1989, pp. 1, 20.

Collins H.M., 1988, Knowing and growing: building an expert system for semi-conductor crystal growing, paper read at 1988 Meeting of the American Anthropological Association, Phoenix, November 1988, cited in Leith (1990). A more extended treatment is given in Collins (1990).

Collins H.M., 1990, Artificial Experts: Social Knowledge and Intelligent Machines, London, The MIT Press.

Computer Journal,1987, Editorial statement, Computer Journal, $30,3$.

Date C.J., 1986, Null values in database management, in: Relational Database: Selected Writings, Wokingham, Addison-Wesley.

Dingwall R., 1980, Orchestrated encounters: an essay in the comparative analysis of speech-exchange systems, Sociology of Health and Illness, 5, 2. 
Dowie J. \& Elstein A., 1988, Professional Judgement, Cambridge, Cambridge University Press.

Frohlich D. \& Luff P., 1990, Applying the technology of conversation to the technology for conversation, in Luff, Gilbert \& Frohlich (1990).

Fuller S., 1987, Social epistemology: a statement of purpose, Social Epistemology, 1, 1, pp. 1-4.

Galileo Galilei, 1967 [1632], Dialogue Concerning the Two Chief World Systems - Ptolemaic and Copernican, trans. S. Drake, Berkeley \& Los Angeles, University of California Press.

Garfinkel H., 1967, Studies in Ethnomethodology, Englewood Cliffs, New Jersey, Prentice-Hall.

Gilbert N., Wooffitt R. \& Fraser N., 1990, Organising computer talk, in Luff, Gilbert \& Frohlich (1990).

Hammersley M. \& Atkinson P., 1983, Ethnography, Principles in Practice, London, Tavistock Publications.

Heritage J.C., 1984, Garfinkel and Ethnomethodology, Cambridge, Polity Press.

Henderson J., 1991, Paying the price of AI in integrity, letter to THES, 11 January 1991.

Hoare C.A.R., 1984, Programming: sorcery or science?, IEEE Software, April, pp. 5-16.

Hume D., 1911 [1738], A Treatise of 'Human Nature, London, Dent.

ISO (1982), Concepts and Terminology for the Conceptual Schema and the Information Base, (ed.) J J van Griethuysen, Publication No. ISO/TC97/SC5 - N695.

Klein H.K. \& Hirschheim R.A., 1987, A comparative framework of data modelling paradigms and approaches, Computer Journal, 30, 1, pp. 8-15.

Kuhn T.S., 1970, The Structure of Scientific Revolutions, second edition, Chicago, The University of Chicago Press.

Latour B., 1987, Science in Action, Milton Keynes, The Open University Press.

Leith P., 1986, Fundamental errors in legal logic programming, Computer Journal, 29, 6.

Leith P., 1990, Formalism in AI and Computer Science, London, Ellis Horwood.

Lopez B., 1987, Arctic Dreams, London, Pan. 
Jossey-Bass.

Shaw M., 1984, The impact of modelling and abstraction concerns on modern programming languages, in: On Conceptual Modelling, edited by Brodie M.L., Mylopoulos J. \& Schmidt J.W., Berlin, Springer-Verlag.

Silverman D., 1985, Qualitative Methodology and Sociology, Aldershot, Gower.

Sommerville I., 1989, Software Engineering, third edition, Wokingham, Addison-Wesley.

Steel T. B., 1985, A minimal conceptual schema language for life, the universe and everything, in: Database Semantics (DS-1) Preliminary (Participant's) Proceedings, IFIP TC2 WG2.6, edited by Steel T.B. \& Meersman R.

Strong P.M., 1979, Sociological imperialism and the profession of medicine: a critical examination of the thesis of medical imperialism, Social Science \& Medicine, 13A, cited in Ashmore, Mulkay \& Pinch (1989).

Suchman L.A., 1987, Plans and Situated Actions, Cambridge, Cambridge University Press.

Toulmin, S., 1953, The Philosophy of Science, London, Hutchinson.

UDACE 1991, What Can Graduates Do?, Unit for the Development of Adult Continuing Education, consultative document.

von Grey M.L., 1990, A look at the benefits of an integrated nursing system, Information Technology in Nursing, 2, 3, pp. 40-41.

Wilks Y., 1991, Ignorance and snobbery about AI, letter to THES, 4 January 1991.

Wittgenstein L., 1958, Philosophical Investigations, Oxford, Basil Blackwell.

Woolgar S., 1983, Irony in the social study of science, in: Science Observed, edited by Knorr-Cetina K.D. \& Mulkay M., London, Sage, pp. 239-266.

Woolgar S., 1985, Why not a sociology of machines? The case of sociology and artificial intelligence, Sociology, 9, 4, pp. 557572.

Woolgar S., 1988, Science: The Very Idea, Chichester and London, Ellis Horwood and Tavistock Publications.

Xargle, 1988, Dr Xargle's Book of Earthlets, trans. J. Willis and T. Ross, London, Andersen Press. 
Luff P., Gilbert N., Frohlich D. (eds.), 1990 Computers and Conversation, London, Academic Press.

Marx K., 1976 [1848], Theses on Feuerbach, in: Karl Marx, Frederick Engels, Collected Works, Volume 5, London, Lawrence \& Wishart, pp. 2-5.

Milner R., 1986, Is computing an experimental science?, Laboratory for Foundations of Computer Science Report ECS-LFCS-86-1

Mumford E., Land F. \& Hawgood J., 1987, A participative approach to the design of computer systems, in: Information Analysis Selected Readings, edited by Galliers R., Reading, Massachusetts, Addison-Wesley.

Norman M. \& Thomas P., 1990, The very idea, in Luff, Gilbert \& Frohlich (1990).

Nursing Specialist Group 1990, Proceedings from Information Technology - Beyond the Theory 1990, Information Technology in Nursing, $2,4$.

Nye A., 1990, Words of Power, London, Routledge.

O'Connor S., 1990, The emperor's new clothes, in: I Do Not Want What I'Haven't Got, London, Chrysalis Records.

Penrose, R., 1990, The Emperor's New Mind, London, Vintage.

Ravetz J.R., 1973, Scientific Knowledge and its Social Problems, Harmondsworth, Penguin.

Robinson H.M., 1990, Towards a sociology of human-computer interaction, in Luff, Gilbert \& Frohlich (1990).

Robinson H.M., 1991, The mechanisation of knowledge, in: Knowledge for Nursing, edited by Robinson K.S. \& Vaughan B., forthcoming, London, Heinemann.

Robinson K.S.M., 1987, The social construction of health visiting, unpublished $\mathrm{PhD}$ thesis, South Bank Polytechnic.

Ryan B., 1991, AI's identity crisis, Byte, January 1991, pp. 239-246.

Sacks H., Schegloff E.A. \& Jefferson G., 1974 A simplest systematics for the organisation of turn-taking for conversation, Language, 50, pp. 686-735.

Saxby S., 1991, Review of Formalism in AI and Computer Science (Leith 1990), THES, 22 February 1991.

Schön D.A., 1983, The Reflective Practitioner, London, TempleSmith.

Schön D.A., 1987, Educating the Reflective Practitioner, London, 
Xargle, 1989, Dr Xargle's Book of Earth Hounds, trans. J. Willis and T. Ross, London, Andersen Press. 